\title{
Can preoperative thyroglobulin antibody levels be used as a marker for well differentiated thyroid cancer?
}

\author{
S. Hosseini ${ }^{1}$, R. J. Payne ${ }^{2}$, F. Zawawi ${ }^{2,3}$, A. Mlynarek ${ }^{2}$, M. P. Hier ${ }^{2}$, M. Tamilia ${ }^{4}$ and V. I. Forest ${ }^{2 *}$
}

\begin{abstract}
Background: It has been reported that thyroglobulin antibody are more frequently elevated in patients with thyroid cancercompared to general population. This study aims at evaluating whether preoperative thyroglobulin antibody (TgAb) levels increase the likelihood that a thyroid nodule is malignant.

Methods: A retrospective review of 586 patients who underwent thyroidectomy was conducted. Demographic data, TgAb levels, and final histopathology were recorded. Patients were divided into two groups: TgAb positive (defined as $\mathrm{TgAb} \geq 30 \mathrm{IU} / \mathrm{ml}$ ) and $\mathrm{TgAb}$ low/negative (defined as $\mathrm{TgAb}<30$ ).

Results: Preoperative TgAb levels were available in 405 patients. There were 353 (87\%) patients in the TgAblow/ negative group (malignancy rate: $50.42 \%$ ) and $52(13 \%)$ patients in the TgAb positive group (malignancy rate: $65.38 \%$ ). The sensitivity, specificity, positive predictive value and negative predictive value of $\mathrm{TgAb} \geq 30 \mathrm{IU} / \mathrm{ml}$ for thyroid malignancy were $16.04 \%, 90.67 \%, 65.38 \%$ and $49.58 \%$, respectively. The relative risk of having a malignant thyroid nodule when the TgAb titers were $\geq 30 \mathrm{IU} / \mathrm{ml}$ was 1.30 (Cl1.04-1.62) and the odds ratio was 1.86 (Cl 1.01-3.41). Both the Pearson chi-square test $(p=0.024)$ and Fisher's exact test $(p=0.017)$ yielded statistical significance between the two groups.

Conclusions: In this study, patients with preoperative TgAb $\geq 30 \mathrm{IU} / \mathrm{ml}$ had a higher rate of malignancy when compared topatients with $\mathrm{TgAb}<30 \mathrm{IU} / \mathrm{ml}$. This suggests that an elevated TgAb level may indicate that a thyroid nodule is at an increased risk for malignancy.
\end{abstract}

\section{Background}

Thyroid nodules are commonly encountered in the general population. It is estimated that there is a 5 to $10 \%$ lifetime risk of having a thyroid nodule [1]. Among all thyroid nodules, about $5 \%$ are cancerous independently of their size [2]. With the steady rise in the detection rate of thyroid nodules, there has been increased interest to identify parameters that can be used as risk factors and predictors of thyroid cancer [3-5].

As a matter of fact, in an attempt to identify other risk factors to help with risk stratification, serum thyroglobulin ( $\mathrm{Tg}$ ) and their antibodies have been studied. Previous reports have shown a relationship between elevated measurements of $\mathrm{Tg}$ and well-differentiated thyroid

\footnotetext{
* Correspondence: viforest@yahoo.ca

${ }^{2}$ Department of Otolaryngology - Head and Neck Surgery, McGill University, Montreal, QC, Canada

Full list of author information is available at the end of the article
}

carcinoma (WDTC). $\mathrm{Tg}$ has been recognized as an established tumor marker for thyroid cancer [6-9]. However, serum thyroglobulin antibody (TgAb) levels may interact with $\mathrm{Tg}$ and give a lower serum $\mathrm{Tg}$ value. In fact, $\mathrm{Tg}$ complexed with $\mathrm{TgAb}$ cannot be detected by the currently available immunometric assay methods, which impairs in those cases the clinical utility of $\mathrm{Tg}$ as a prognostic factor for WDTC. However, this has lead to another question on the potential significance of $\mathrm{TgAb}$ in risk stratification of thyroid nodule.

Depending on the population studied and the assay used, $\operatorname{TgAb}$ levels are elevated in approximately $20 \%$ of patients with WDTC, as compared to $10 \%$ of individuals in the general population [10]. Also, high titers of $\operatorname{TgAb}$ are present in the serum of most patients with chronic lymphocytic thyroiditis (CLT). In 2010, Kim et al. reported for the first time that a positive $\operatorname{TgAb}$ test was an independent predictor of thyroid nodule 
malignancy, regardless of the presence of CLT [11]. Subsequently, other reports showed conflicting results. The aim of the present study is to assess whether higher levels of preoperative $\operatorname{TgAb}$ correlate with an increased likelihood of a thyroid nodule being malignant.

\section{Methods}

This study is a retrospective review of 586 patients who underwent a thyroidectomy by a single surgeon at the McGill University teaching hospitals between January 2012 and December 2013. Our investigation obtained ethics approval by the McGill University Health Center Research Ethics Board and the Jewish General Hospital Research Ethics Office.

The inclusion criteria were age $>18$ years old, hemi or total thyroidectomy, and available preoperative $\mathrm{TgAb}$ measurements and final histopathology reports. Patients with final diagnoses other than WDTC were excluded from the study. The histopathology analysis was done according to the World Health Organization Classification of Thyroid Tumors. CLT was identified on histopathological analysis. Data collated included patients' demographic data, final histopathology reports, and preoperative $\mathrm{TgAb}$ measurements.

Patients were divided into two groups based on $\operatorname{TgAb}$ titers: $\mathrm{TgAb}$ positive group, defined as $\mathrm{TgAb} \geq 30 \mathrm{IU} / \mathrm{ml}$, and $\mathrm{TgAb}$ low/negative group, defined as $\mathrm{TgAb}<30 \mathrm{IU} / \mathrm{mL}$. $\operatorname{TgAb}$ levels were measured using the Immulite 2000 anti$\operatorname{TgAb}$ assays (Siemens, Llanberis, United Kingdom).

Patients with an incidental finding of micropapillary thyroid carcinoma without extrathyroidal extension (ETE) and/or lymph node (LN) positivity were recorded as having benign pathology. These carcinomas were categorized as such since they present an indolent behavior and a favorable prognosis, which suggest their resemblance to benign carcinomas [12]. Micropapillary carcinomas with unfavorable histopathological features, such as ETE and/or LN positivity, behave more aggressively and are hence more appropriately managed as malignant carcinomas [12].

Sensitivity, specificity, positive predictive value, negative predictive value, relative risk and odds ratio of $\mathrm{TgAb}$ $\geq 30 \mathrm{IU} / \mathrm{ml}$ as a diagnostic test for thyroid malignancy were calculated. The data was statistically analyzed using SPSS 20.0. Pearson chi-square and Fisher's exact test were used to identify difference between groups. A $p$ value of 0.05 or less was considered statistically significant.

\section{Results}

\section{Clinical characteristics}

Among the 586 patients who underwent thyroid surgery during the study period, 181 were excluded from the study: 174 had incomplete data (TgAb value or final histopathology not available), 6 had medullary carcinoma and 1 had anaplastic carcinoma. Among those with incomplete data, 157 patients had unrecorded $\mathrm{TgAb}$ values but available pathology reports, showing a rate of malignancy of $68.8 \%(108 / 157)$ in this subgroup of patients. A total of 405 patients were included in this study. There were 329 females (81\%) and 76 (19\%) males, giving a female to male ratio of approximately $4: 1$. In the TgAb positive group, $92 \%(48 / 52)$ of the patients were women in comparison to $80 \%(282 / 353)$ in the $\mathrm{TgAb}$ negative group $(p=0.031)$. The mean age in the TgAb positive group was 45 years compared to 50 years in the TgAb negative group $(p=0.013)$.

There were 212 (52 \%) patients with WDTC: $182(86 \%)$ of which had papillary carcinoma, 16 (7 \%) had micropapillary carcinoma with ETE and/or LN positivity, and 14 (7 \%) had follicular carcinoma. There were 193 (48 \%) patients with benign pathology, of which 68 (35\%) had micropapillary carcinoma without ETE and/or LN positivity. The flow chart of this study is shown in Fig. 1. The patient characteristics are presented in Table 1.

Among the 405 patients, 52 (13\%) were found to have $\operatorname{TgAb}$ levels $\geq 30 \mathrm{IU} / \mathrm{mL}$, while the remaining $353(87 \%)$ had $\mathrm{TgAb}$ values $<30 \mathrm{IU} / \mathrm{mL}$. The TgAb values ranged from $<20$ (lowest value detected by the assay used) to 3362. A total of $340(84 \%)$ patients had values $<20$ while the median and mean $\mathrm{TgAb}$ values of the remaining patients were 96 and 412 (standard deviation 739). In the malignant group, 175 (83 \%) patients had $\mathrm{TgAb}$ values $<20$ vs. $165(85 \%)$ in the benign group, while the median and mean TgAb values of the remaining patients were 108 vs. 53 and 751 (standard deviation 1920) vs. 313 (standard deviation 479) respectively.

There were 34 out of the 52 patients in the positive $\mathrm{TgAb}$ group who were diagnosed with WDTC, compared to 178 of the 353 patients in the low/negative $\mathrm{TgAb}$ group, resulting in a malignancy rate of $65 \%$ vs. $50 \%$, respectively $(p=0.05)$. In other words, overall, $16 \%$ of patients with WDTC had positive TgAb levels, compared to $9 \%$ of the patients with a benign pathology (Table 1). The prevalence of malignancy according to TgAb levels is presented in Fig. 2. It is worth noting that within the benign group, $7.4 \%$ of patients with micropapillary carcinoma without ETE and/or LN positivity had TgAb values $\geq 30$ ( 5 out of 68 ) compared to $10.4 \%$ (13 out of 125) of patients with other benign pathologies.

Overall, the final histopathology reports revealed the presence of CLT in 98 out of 405 patients (24.2\%). An approximately equal proportion of patients in both the malignant and benign groups presented with CLT ( $24.5 \%$ vs. $23.8 \%$ respectively). In the TgAb positive group, $50 \%$ of patients with malignant disease had CLT. Similarly, $50 \%$ of patients in the benign group harboured CLT in their thyroids. About $20 \%$ of patients in the $\operatorname{TgAb}$ negative group had CLT, with once again an 


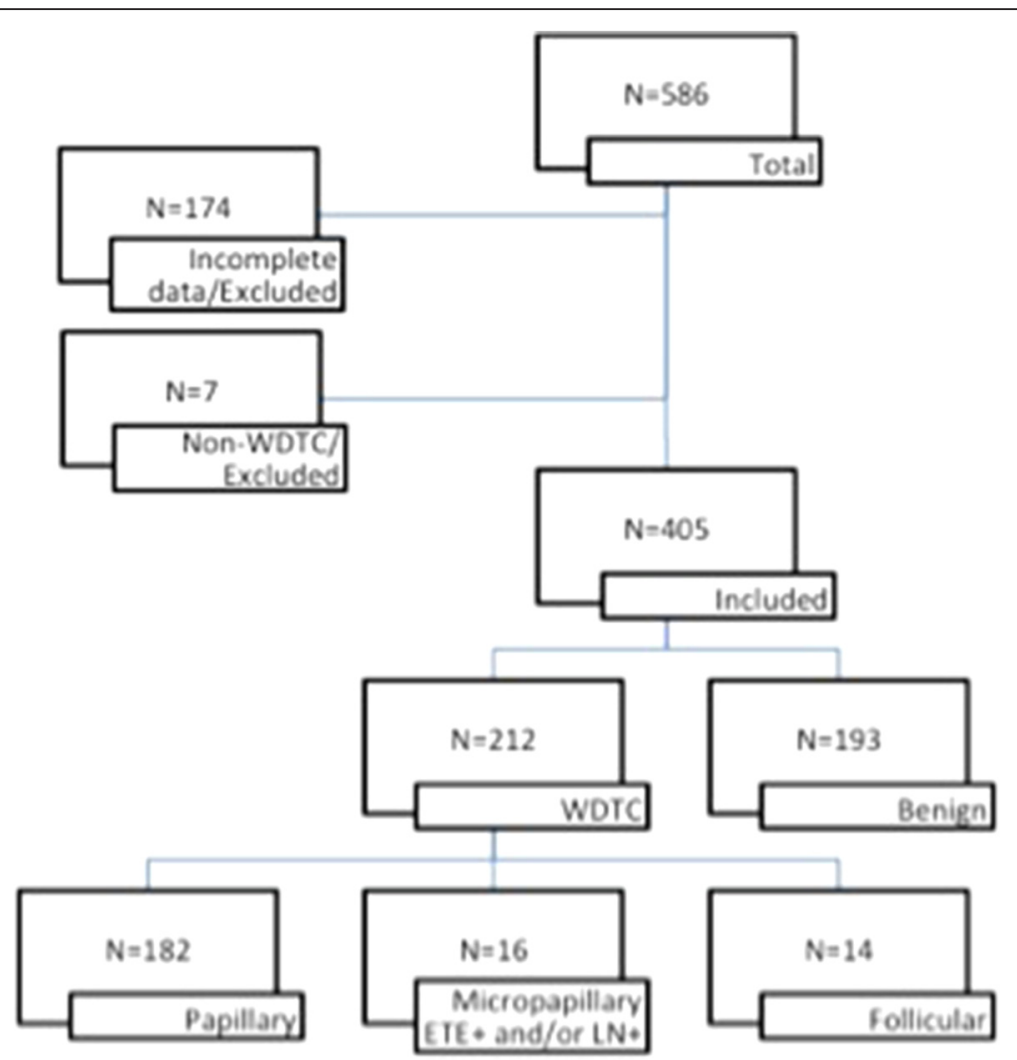

Fig. 1 Flow chart of diagnosis

approximately equal proportion of patients in the malignant and benign groups (19.7 \% vs. $21.1 \%$ respectively). These results are shown in Table 2.

\section{Statistical analysis}

The sensitivity, specificity, positive predictive value and negative predictive value of $\operatorname{TgAb} \geq 30 \mathrm{IU} / \mathrm{ml}$ as a predictive parameter of thyroid malignancy were $16.04 \%$ (CI 11.37-21.68), 90.67 \% (CI 85.66-94.38), 65.38 \% (CI 50.91-78.03) and $49.58 \%$ (CI 44.24-54.92), respectively. Both the Pearson chi-square test $(p=0.024)$ and Fisher's exact test $(p=0.017)$ yielded statistical significance between the two groups.

\section{Discussion}

This study demonstrates that the prevalence of WDTC was higher in patients with positive $\mathrm{TgAb}$, compared to

Table 1 Patient characteristics of the sample $(N=405)$

\begin{tabular}{llll}
\hline & $\begin{array}{l}\text { Benign } \\
(N=193)\end{array}$ & $\begin{array}{l}\text { Malignant } \\
(N=212)\end{array}$ & $p$-value \\
\hline Age (years) & $49.53 \pm 13.94$ & $49.25 \pm 13.87$ & NS \\
Gender, no. female (\%) & $164(84.97)$ & $165(77.83)$ & NS \\
TgAb $\geq 30 \mathrm{IU} / \mathrm{mL}$, no. (\%) & $18(9.33)$ & $34(16.04)$ & 0.024 \\
\hline
\end{tabular}

Data represents mean \pm standard deviation or number (percentage) NS not significant patients with low/negative $\operatorname{TgAb}$. Our results suggest that a TgAb count $\geq 30 \mathrm{IU} / \mathrm{ml}$ may be specific for WDTC, although a lower count should not be used to rule out malignancy. In accordance with our data, other authors have reported that elevated TgAb levels could be an indicator that a thyroid nodule is at increased risk for malignancy. As mentioned earlier, Kim et al. were the first to report that a positive $\operatorname{TgAb}$ test was an independent predictor of thyroid nodule malignancy, regardless of the presence of CLT. A more recent study conducted by Grani et al. showed that an isolated $\mathrm{TgAb}$ positivity could be a mild risk factor for thyroid cancer, as opposed to Hashimoto's thyroiditis, which did not correlate positively with malignant pathology [13].

Our study shows that in the $\operatorname{TgAb}$ positive group, there is a significantly higher proportion of women and patients were slightly younger compared to those in the $\mathrm{TgAb}$ negative group. Demographics and levels of TgAb were examined in the National Health and Nutrition Examination Survey (NHANES III), a large study that was conducted on the American population between 1988 and 1994 [14]. They reported that TgAb were more prevalent in women than in men. However, in this cohort, levels of $\mathrm{TgAb}$ were increasing with age when comparing youth vs adults vs elderly patients. We compared age according to the mean age of both groups which 


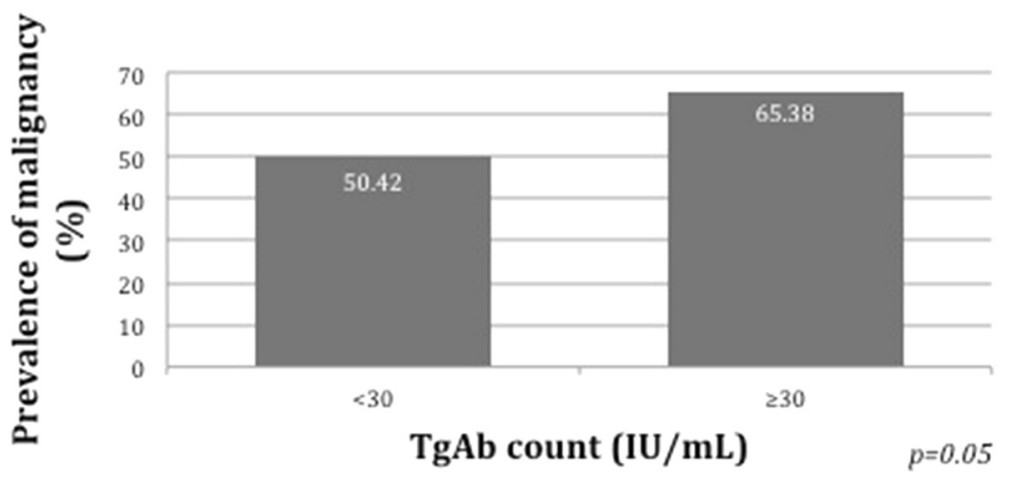

Fig. 2 Prevalence of malignancy according to TgAb levels

could explain the difference in this finding. The age groups were separated differently than our series of patients. Nevertheless, it is relevant to note that they lie in the same age category, as increasing concentrations with age in the NHANES III study was only significant when comparing groups with greater age difference (i.e. youth vs. adults vs. elderly).

Our results show that $50 \%$ of $\mathrm{TgAb}$ positive patients had CLT compared to $20 \%$ of TgAb negative patients. An association between the presence of TgAb and CLT has also been reported in the literature $[15,16]$. However, we did not find a significant correlation between CLT and WDTC, as prevalence of CLT was the same for benign and malignant pathologies. This is in agreement with the literature. In fact, a population-based fineneedle aspiration biopsy study [17] and two large prospective studies with a 10-year follow-up $[18,19]$ did not find an association between CLT and WDTC. Currently, in the literature, there is uncertainty on whether CLT is a cause, a consequence or simply, histologically accompanying a malignancy, as both share some common pathways in molecular genetic pathology. It is also difficult to differentiate histologically between peritumoral lymphocytic infiltrations and true CLT [20-26]. However, most believe that pathologic processes of autoimmune thyroid disease have to be independent from the ones of tumorogenesis to explain the increased prevalence of CLT in TgAb positive patients.

Table 2 Prevalence of specimens showing chronic lymphocytic thyroiditis according to TgAb group and final pathology

Number of specimens with CLT/total number of specimens (\%)

\begin{tabular}{llll}
\hline & Benign & Malignant & Total \\
\hline TgAb $\geq 30$ & $9 / 18(50)$ & $17 / 34(50)$ & $26 / 52(50)$ \\
TgAb $<30$ & $37 / 175(21.1)$ & $35 / 178(19.7)$ & $72 / 353(20.4)$ \\
Total & $46 / 193(23.8)$ & $52 / 212(24.5)$ & $98 / 405(24.2)$ \\
\hline
\end{tabular}

CLT Chronic lymphocytic thyroiditis
In the aforementioned studies by Kim et al. [11] and Grani et al. [13], the patient's final diagnostic outcome was established following FNAC, with only a minority of diagnoses confirmed by histological follow-up. One limitation of using FNAC as a diagnostic tool is that the cytological features observed in the sample obtained are not necessarily representative of the entire thyroid tissue and cannot consequently offer a definitive diagnosis. An alternative to this problem consists of using the final pathology report obtained after surgical excision, which is the only diagnostically conclusive method. However, the latter also presents limitations, namely the bias caused by the selection of patients with high suspicion of thyroid cancer, and hence requiring thyroidectomy. In order to balance this selection bias, our study focused on the comparison between a $\operatorname{TgAb}$ positive and $\mathrm{a} \operatorname{TgAb}$ negative group. Moreover, selecting a sample of surgical candidates was especially relevant in the context where risk assessment algorithms are particularly needed for patients in whom surgery is considered a treatment option. It is worth noting that another source of potential selection bias stems from the relatively high malignancy rate $(68.8 \%)$ in patients excluded from the study due to unavailable $\mathrm{TgAb}$ values.

Finally, it is important to mention that in the current literature there is no defined threshold of what is considered an elevated $\operatorname{TgAb}$ titer in WDTC. Most studies published set their cut-off values according to the recommendations of the assay kit provided by the manufacturer, which are calculated for its use in the diagnosis of CLT. When used for that purpose, the cut-offs are set higher as it is believed that higher titers of $\mathrm{TgAb}$ are needed to interfere with $\mathrm{Tg}$ levels in patients with CLT compared to WDTC [27]. In fact, two studies suggested that up to $20 \%$ of samples may be misclassified as $\operatorname{TgAb}$ negative when the manufacturer's cut-off levels are used, as they are set too high $[28,29]$. Since the manufacturer of the assay we used recommended a cut-off of $40 \mathrm{IU} /$ 
$\mathrm{mL}$, we lowered it to $30 \mathrm{IU} / \mathrm{mL}$ in an effort to capture more patients with potentially interfering $\mathrm{TgAb}$ values. This implies that a threshold of $30 \mathrm{IU} / \mathrm{mL}$ may not be transferable to centres using a different anti-TgAb assay with variable manufacturer's recommendations. The reason for establishing the threshold to 30 and not to some other value below 40 relates to the statistical analysis of the test; a value of 30 offered the highest specificity among values showing statistical significance between the two groups.

Another limitation of our study is that it is retrospective. On one hand, this approach allowed us to accumulate data for a large number of cases; on the other hand, it limited our access to complete information for a number of patients. Nevertheless, we believe that the impact on the validity of our results is minimal as our results are concordant with other reports published in the literature. The results of the current study show that patients with elevated $\mathrm{TgAb}$ levels have a significantly higher rate of malignancy compared to patients with lower levels. However, this needs to be interpreted in the context of the aforementioned limitations. As such, incorporating TgAb levels measurement in the preoperative risk assessment of patients presenting with thyroid nodules could be helpful to predict malignancy when used with other variables. Nevertheless, an isolated $\mathrm{TgAb}$ test alone is not powerful enough and should not influence decision-making. Our results need confirmation from larger, prospective studies to better clarify the potential role of serum TgAb levels in the prediction of thyroid malignancy.

\section{Conclusions}

Incorporating $\mathrm{TgAb}$ levels measurement in the preoperative risk assessment of patients presenting withthyroid nodules could be helpful to predict malignancy when used with other variables. Nevertheless, an isolated $\mathrm{TgAb}$ test alone is not powerful enough and should not influence decision-making. Our results need confirmation from larger, prospective studies to better clarify the potential role of serum $\mathrm{TgAb}$ levels in theprediction of thyroid malignancy.

\section{Competing interests}

The authors declare that they have no competing interests.

\section{Authors' contributions}

SH, and FW carried out the data collection, statistical analysis and drafted the manuscript. All authors read and approved the final manuscript.

\section{Author details}

${ }^{1}$ Faculty of Medicine, McGill University, Montreal, QC, Canada. ${ }^{2}$ Department of Otolaryngology - Head and Neck Surgery, McGill University, Montreal, QC, Canada. ${ }^{3}$ Department Otolaryngology - Head and Neck Surgery, King Abdulaziz University, Jeddah, Saudi Arabia. ${ }^{4}$ Division of Endocrinology, Jewish General Hospital, McGill University, Montreal, QC, Canada.

Received: 2 October 2015 Accepted: 4 May 2016

Published online: 14 May 2016

\section{References}

1. Mazzaferri EL. Management of a solitary thyroid nodule. N Engl J Med. 1993; 328(8):553-9.

2. Hegedus L. Clinical practice. The thyroid nodule. N Engl J Med. 2004;351(17): 1764-71.

3. Yassa L, Cibas ES, Benson CB, Frates MC, Doubilet PM, Gawande AA, Moore FD Jr, Kim BW, Nose V, Marqusee E, Larsen PR, Alexander EK. Long-term assessment of a multidisciplinary approach to thyroid nodule diagnostic evaluation. Cancer. 2007;111:508-16.

4. Hayat MJ, Howlader N, Reichman ME, Edwards BK. Cancer statistics, trends, and multiple primary cancer analyses from the Surveillance, Epidemiology, and End Results (SEER) program. Oncologist. 2007;12:20-37.

5. Brander A, Viikinkoski P, Tuuhea J, Voutilainen L, Kivisaari L. Clinical versus ultrasound examination of the thyroid gland in common clinical practice. J Clin Ultrasound. 1992;20:37-42.

6. Scheffler P, Forest VI, Leboeuf R, Florea AV, Tamilia M, Sands NB, et al. Serum thyroglobulin improves the sensitivity of the McGill thyroid nodule score for well-differentiated thyroid cancer. Thyroid. 2014;24(5):852-7.

7. Sands NB, Karls S, Rivera J, Tamilia M, Hier MP, Black MJ, Gologan O, Payne RJ. Preoperative serum thyroglobulin as an adjunct to fine-needle aspiration in predicting well-differentiated thyroid cancer. J Otolaryngol Head Neck Surg. 2010;39:669-73.

8. Hocevar M, Auersperg M. Role of serum thyroglobulin in the pre-operative evaluation of follicular thyroid tumours. Eur J Surg Oncol. 1998;24:553-7.

9. Lee EK, Chung KW, Min HS, Kim TS, Kim TH, Ryu JS, Jung YS, Kim SK, Lee YJ. Preoperative serum thyroglobulin as a useful predictive marker to differentiate follicular thyroid cancer from benign nodules in indeterminate nodules. J Korean Med Sci. 2012;27:1014-8.

10. Spencer CA. Clinical review: Clinical utility of thyroglobulin antibody (TgAb) measurements for patients with differentiated thyroid cancers (DTC). J Clin Endocrinol Metab. 2011;96(12):3615-27.

11. Kim ES, Lim DJ, Baek KH, Lee JM, Kim MK, Kwon HS, et al. Thyroglobulin antibody is associated with increased cancer risk in thyroid nodules. Thyroid. 2010;20(8):885-91.

12. Ardito G, Revelli L, Giustozzi E, Salvatori M, Fadda G, Ardito F, et al. Aggressive papillary thyroid microcarcinoma: prognostic factors and therapeutic strategy. Clin Nucl Med. 2013;38(1):25-8.

13. Grani G, Calvanese A, Carbotta G, D'Alessandri M, Nesca A, Bianchini M, et al. Thyroid autoimmunity and risk of malignancy in thyroid nodules submitted to fine-needle aspiration cytology. Head Neck. 2013;24(5):852-7.

14. Hollowell JG, Staehling NW, Flanders WD, Hannon WH, Gunter EW, Spencer CA, et al. Serum TSH, T(4), and thyroid antibodies in the United States population (1988 to 1994): National Health and Nutrition Examination Survey (NHANES III). J Clin Endocrinol Metab. 2002;87(2):489-99.

15. Toyoda N, Nishikawa M, Iwasaka T. Anti-thyroglobulin antibodies. Nihon Rinsho. 1999;57(8):1810-4.

16. Farwell AP, Braverman LE. Inflammatory thyroid disorders. Otolaryngol Clin North Am. 1996;29(4):541-56.

17. Jankovic B, Le KT, Hershman JM. Clinical Review: Hashimoto's thyroiditis and papillary thyroid carcinoma: is there a correlation? J Clin Endocrinol Metab. 2013;98(2):474-82

18. Crile G. Struma lymphomatosa and carcinoma of the thyroid. Surg Gynecol Obstet. 1978;147:350-2.

19. Holm LE, Blomgren H, Lo"whagen T. Cancer risks in patients with chronic lymphocytic thyroiditis. N Engl J Med. 1985;312:601-4.

20. Wirtschafter A, Schmidt R, Rosen D, Kundu N, Santoro M, Fusco A, Multhaupt H, Atkins JP, Rosen MR, Keane WM, Rothstein JL. Expression of the RET/PTC fusion gene as a marker for papillary carcinoma in Hashimoto's thyroiditis. Laryngoscope. 1997;107:95-100.

21. Arif S, Blanes A, Diaz-Cano SJ. Hashimoto's thyroiditis shares features with early papillary thyroid carcinoma. Histopathology. 2002;41:357-62.

22. Unger P, Ewart M, Wang BY, Gan L, Kohtz DS, Burstein DE. Expression of p63 in papillary thyroid carcinoma and in Hashimoto's thyroiditis: a pathobiologic link. Hum Pathol. 2003;34:764-9.

23. Larson SD, Jackson LN, Riall TS, Uchida T, Thomas RP, Qiu S, Evers BM. Increased incidence of well-differentiated thyroid cancer associated with Hashimoto thyroiditis and the role of the PI3k/Akt pathway. J Am Coll Surg. 2007:204:764-75.

24. Kang DY, Kim KH, Kim JM, Kim SH, Kim JY, Baik HW, Kim YS. High prevalence of RET, RAS, and ERK expression in Hashimoto's thyroiditis and in papillary thyroid carcinoma in the Korean population. Thyroid. 2007;17:1031-8. 
25. Antonaci A, Consorti F, Mardente S, Giovannone G. Clinical and biological relationship between chronic lymphocytic thyroiditis and papillary thyroid carcinoma. Oncol Res. 2009;17:495-503.

26. Muzza M, Degl'Innocenti D, Colombo C, Perrino M, Ravasi E, Rossi S, Cirello V, Beck-Peccoz P, Borrello MG, Fugazzola L. The tight relationship between papillary thyroid cancer, autoimmunity and inflammation: clinical and molecular studies. Clin Endocrinol (Oxf). 2010;72:702-8.

27. Verburg FA, Luster M, Cupini C, Chiovato L, Duntas L, Elisei R, et al. Implications of thyroglobulin antibody positivity in patients with differentiated thyroid cancer: a clinical position statement. Thyroid. 2013; 23(10):1211-25.

28. Spencer C, Petrovic I, Fatemi S. Current thyroglobulin autoantibody (TgAb) assays often fail to detect interfering $\operatorname{TgAb}$ that can result in the reporting of falsely low/undetectable serum Tg IMA values for patients with differentiated thyroid cancer. J Clin Endocrinol Metab. 2011:96:1283-91.

29. Cubero JM, Rodriguez-Espinosa J, Gelpi C, Estorch M, Corcoy R. Thyroglobulin autoantibody levels below the cut-off for positivity can interfere with thyroglobulin measurement. Thyroid. 2003;13:659-61.

Submit your next manuscript to BioMed Central and we will help you at every step:

- We accept pre-submission inquiries

- Our selector tool helps you to find the most relevant journal

- We provide round the clock customer support

- Convenient online submission

- Thorough peer review

- Inclusion in PubMed and all major indexing services

- Maximum visibility for your research

Submit your manuscript at www.biomedcentral.com/submit
Biomed Central 